\title{
LASER-INDUCED PLASMA EMISSION SPECTROSCOPY (LIPS): A USEFUL ANALAYTICAL TOOL FOR THE SURFACE CHEMICAL CHARACTERIZATION OF COATED PAPER MATERIALS
}

\author{
Lucian A. Lucia, ${ }^{\mathrm{a}, *}$ Brian Willett, ${ }^{\mathrm{b}}$ Jouko Korppi-Tommola ${ }^{\mathrm{c}}$
}

\begin{abstract}
A nontraditional method for chemical analysis of light weight coated (LWC) grade paper is described. Laser-induced plasma emission spectrometry (LIPS) produces three-dimensional profiles of coatings and fillers. The technique ablates the coating from the top to the paper base with a laser beam. LIPS provides spatial resolution and characterization of the chemical homogeneity of the paper coating and relates that information to the efficiency of the coating method. It provides information on binder migration which is a hindrance for improved stable coatings. Herein, several commercial LWC paper grades and their base papers were analyzed. Pigment identification of light weight paper coatings, coat weight distribution maps, and profiles were obtained. Blade and film coating generate different coating distribution profiles that are detected by LIPS. The phenomenon of binder migration was demonstrated by observing its masking effects on Si spectra. An investigation of filler content in base papers involved analysis of base paper used in LWC grades. The papers represented two different types of formers, but because of confidentiality issues, little else was revealed. A significantly higher amount of filler was observed at the surface of the base stock in Former A than in Former B, as indicated from Mg spectra of the filler.
\end{abstract}

Keywords: Laser ablation, Light weight coating, Spectroscopy, Plasma, Binder

Contact information: a: Department of Wood and Paper Science, North Carolina State University, Campus Box 8005, Raleigh, North Carolina 27695-8005 b: Institute of Paper Science and Technology, Georgia Institute of Technology, 500 Tenth Street NW, Atlanta, Georgia 30332-0620; c: University of Jyväskylä, Department of Chemistry, P.O. Box 35, Jyväskylä, Finland 40014; *Corresponding author: lucian.lucia@,NCSU.edu

\section{INTRODUCTION}

LIPS is a nontraditional surface analytical technique for coated paper substrates, whose capacity to perform surface profilometry is among the best available. It is essentially a surface analytical technique that uses laser light to thermally ablate the top layer of a substrate to identify the chemical constituents (both organic and inorganic) of the ablated layer. Its appeal is evident in the simplicity of its functionality, its ability to probe almost any surface, and in the quality of the data it provides.

The issues of coating formation, homogeneity, and stability have plagued paper coatings for many years and do not have an efficient technology or method to gauge their level of quality. Therefore, methods to probe these issues improve the economics and quality of coatings. In general, the goals of applying a coating to a base paper stock are to cover the surface of the base paper with a microporous layer and to smooth out any unevenness in the base (Kartovaara 1989). Paper coatings are applied to paper in order to 
improve its smoothness, opacity, gloss, and printability. They comprise a wide and varied array of inorganic pigments, organic binders, and adhesives and additives. Many coating formulations are of a proprietary nature, although the composition of most coating formulations is quite similar. These components are all amenable to chemical investigation as a function of spatial location in the coating by LIPS. This method may allow the paper coatings sector to develop a greater appreciation of which coating technologies lend themselves to better, smoother, glossier applications, and which are most stable. The work presented here was conducted to provide preliminary data on the technique, its application to commercial paper coatings, and to elucidate differences in the commercial coatings under study.

\section{Coating Technologies}

Fig. 1 illustrates simplified, magnified cross sections of paper coatings prepared by three different techniques. The air knife coater provides a uniform coating layer that follows the contour of the sheet. The roll coater provides good coating coverage, but patterning defects are introduced as a result of film splitting (Smook 1992). Roll coaters do not provide the same high degree of smoothness as that provided by blade coaters. The blade coater sacrifices uniform coating thickness across the sheet by distributing thicker coating applications into the low relief areas of the sheet, resulting in a smoother sheet.

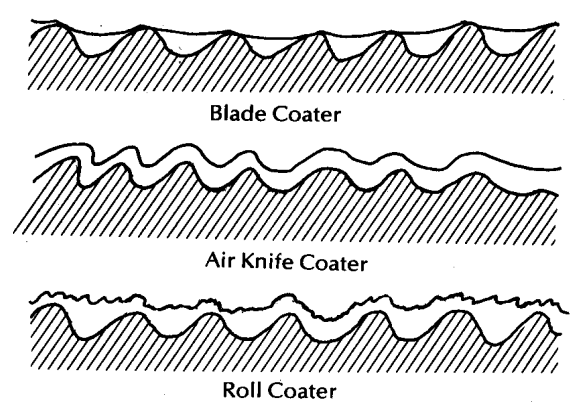

Fig. 1. A representation of the cross section of paper coated by three different methods.

The success of a commercial coating operation requires that the coating formulation be stable, evenly colored, and not tend to weep or scratch during application to paper. Fig. 2 is a highly simplified representation of how a cationic polymer additive can assist in the preparation of a homogeneous formulation through charge-charge interactions. The left-hand image represents the anionic charge character of various surfaces and colloidal matter within a coating formulation (excluding the necessary monoatomic cations for electroneutrality) with emphasis on the charged internal periphery of the coating. In general, such an anionically-stabilized formulation has only a limiting ability to resist particle-to-particle sticking collisions, especially when under mechanical stress during a coating operation. The middle image is a cartoon representation of a general polycationic additive. The final result, as shown in the righthand image, represents a way in which a polycationic polymer can enhance the overall flow of the formulation by adsorbing in a three-dimensional manner onto the surfaces of the dispersed materials. The colloidal stability of the coating formulation is enhanced due 
to the somewhat extended conformation of the adsorbed polycation chains; close approach of such particles is unfavorable due to a reduction in conformational entropy when the adsorbed layers become squeezed. An expected result is more uniform flow, yielding a more homogeneous application of coating materials. In addition, the ability of cationic polyelectrolytes eventually to form macromolecular bridges between negatively charged materials is expected to favor gradual immobilization of the coating formation, reducing a tendency for weeping after the coating has been applied to paper.

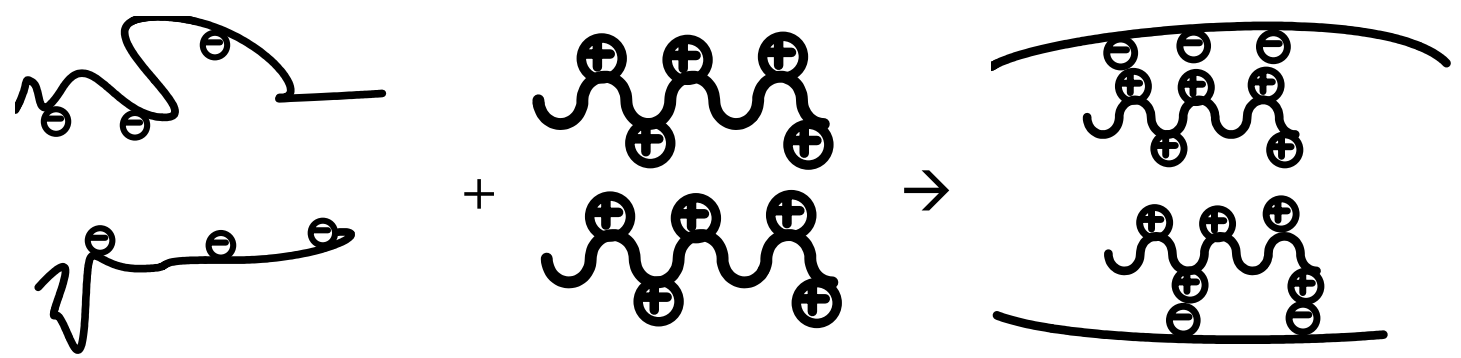

Fig. 2. A simplified representation of an enhanced flow condition induced in a coating formulation via a cationic polyelectrolyte-bulk anionic coating charge interaction.

\section{Laser Induced Plasma Emission Spectrometry (LIPS)}

Laser-induced plasma emission spectroscopy (LIPS) or Laser-induced breakdown spectroscopy (LIBS) is an analytical tool that utilizes elemental spectral emission lines generated from a laser-induced plasma. Laser ablation technologies have steadily developed over the past 40 years, starting with the construction of the first ruby laser by Maiman (1960). Today's lasers are far more sophisticated, powerful, and portable, but the principles governing laser ablation spectroscopy remain unchanged. The method has been employed in the elemental analysis of materials, including, among others, metals (Autin et al. 1993), metal ores (Grant et al. 1991), aerosols (Radziemski 1983), ceramics (Heitz 1997), soils (Eppler et al. 1996), human tissue (Samek et al. 2001), artwork (Anglos et al. 1997), detection and identification of bacteria (Baudelet et al. 2006), hazardous materials (Whitehouse 2006), aerosol compositions (Chen et al. 2005), and paper (Hakkanen 1998; Hakkanen and Korppi-Tommola 1998; Hakkanen and KorppiTommola 1995).

A representation of the system which was used in the present study is shown in Fig. 3. As shown, the spectrometer used for this type of analysis consists of three components: (i) a light source (LASER in block diagram) and a computer-controlled system to control the laser pulse energy (ii) a sample translation stage (all intermediate components between laser and collection at the ICCD/SPECTROGRAPH), and (iii) a spectrometer with a time resolved multi-channel detection system (ICCD \& Spectrograph) (Hakkanen 1998a). The light source is an ArF excimer laser (193 nm), which is capable of generating a cold plasma. Cold plasmas consist mainly of neutral atoms that provide high emission intensities of spectral lines and maintain a good signalto-background ratio. 


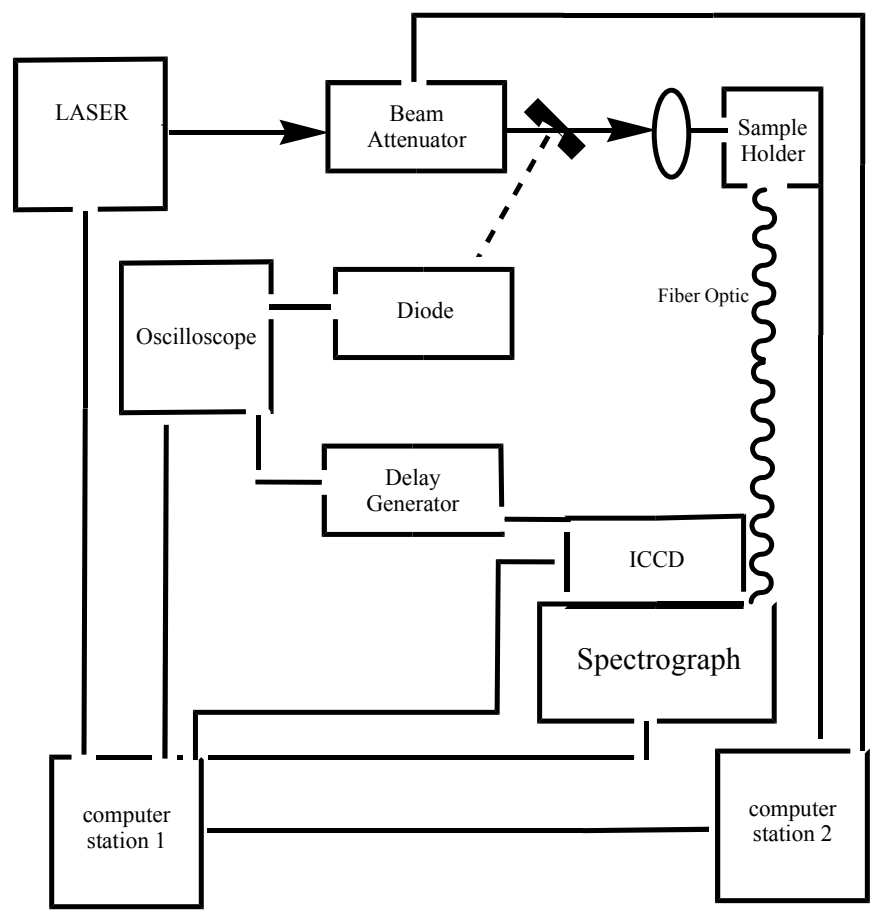

Fig. 3. A simplified block diagram representation of the LIPS system that was used in this study which is available at the Department of Chemistry, University of Jyväskylä (Finland).

Analyses are carried out while blowing ambient air at atmospheric pressure onto the focal area in the sample holder. Pulse durations are normally of a $15 \mathrm{~ns}$ full width half height (fwhh) spectral window. A computer controlled beam attenuator is used to control both laser energy and intensity. The attenuator adjusts the beam by tilting two filters (wg $280 \mathrm{Schott}$ ) simultaneously in opposite directions. Depending on the spot diameter, laser pulse energies are varied from $0.2 \mathrm{~mJ}$ to $0.9 \mathrm{~mJ}$. For this work, pulse energies were maintained at $5 \mathrm{~mJ}$. Laser pulse energy is continuously computer monitored throughout the analysis. The laser beam was focused at normal incidence to the sample using $50 \mathrm{~mm}$ long quartz lenses. The sample holder consists of an aluminum cylinder upon which the paper sample is mounted. The cylinder and the sample are translated in both the $\mathrm{X}$ and $\mathrm{Y}$ direction using a computer controlled step motor. Light emissions from the plasma plume are carried via a fiber optic bundle to a spectrograph. A gated Intensified Charged Coupling Device (ICCD) using a spectral range of 185-215 $\mathrm{nm}$, the optimal wavelength range for paper coatings, detected the spectrally resolved light. Finally, a digital delay pulse generator with a $50 \mathrm{~ns}$ delay time was used to optimize the emission signals from the spectrally resolved light.

It is the analysis of these neutral atom spectral lines that provides the signature elemental composition of the ablated material. Plasma formation is dependent on wavelength, with absorption of laser radiation as the mechanism for the near infrared (NIR) region, and multi-photon ionization as the mechanism in the ultraviolet (UV) region. 
A number of factors affect the nature of the generated plasma plume These include laser light wavelength and energy, plasma temperature, physical properties of the target material and atmospheric operating conditions. These factors, in turn, determine the reliability of the emission spectra for analytical purposes. Calibrations and corrections are normally built in to most laser hardware and software set-ups to account for or correct these factors. Several considerations should be discussed regarding the specifics of the hardware used in the LIPS set-up. In optimizing the LIPS method, it was decided to minimize the amount of ablated material while maximizing the signal-tobackground noise. This was accomplished by using a low pulse energy (less than $60 \mathrm{~mJ}$ ) and short pulse durations (less than $100 \mathrm{~ns}$ ). Laser light wavelength in the lower UV range was also used, since this mainly generates neutral atom ions.

Another parameter that was considered in the LIPS set-up was matrix effects. Paper is, by its very nature, an inhomogeneous solid, consisting of fibers, fines, fillers, coating pigments and various additives. Similarly, a mineral pigment, such as kaolin, is not homogeneous throughout the sample, as minor impurities within the crystal lattice can cause variable signal intensities. For quantitative results, a calibration is therefore necessary for each sample which was obtained.

LIPS has a number of advantages for purposes such as analysis of paper samples. One of the most important is providing rapid 3-dimensional analysis of substrates. A 10 $\mathrm{cm}$ profile of LWC paper with measurements taken every $100 \mathrm{um}$, using 20 shots/point, takes approximately 30 minutes. Relatively large areas of coated paper $\left(4 \mathrm{~cm}^{2}\right)$ can be analyzed in less than an hour. There is no sample preparation and no contamination, since the analysis is strictly of an optical nature. Both quantitative and qualitative data can also be obtained from this analysis.

Some of the more common pigments used in paper coatings and fillers are kaolin and calcium carbonate. LIPS spectra for a coated paper sample containing mixed kaolin and calcium carbonate is shown in Figure 4 (Hakkanen 1998a). The spectrum was detected using the same LIPS setup as was used in this work. Carbon and calcium lines are from the calcium carbonate and binder. Silicon and aluminum lines originate from the kaolin. Magnesium lines come from impurities in both pigments. Another potential source of magnesium is talc, which is often added at the wet end of paper machines for control of pitch deposition. It should be noted that a narrower wavelength range can and should be used for most paper coating analyses since relevant elements show useful emission lines in this range, and a better resolution of line intensities can be obtained.

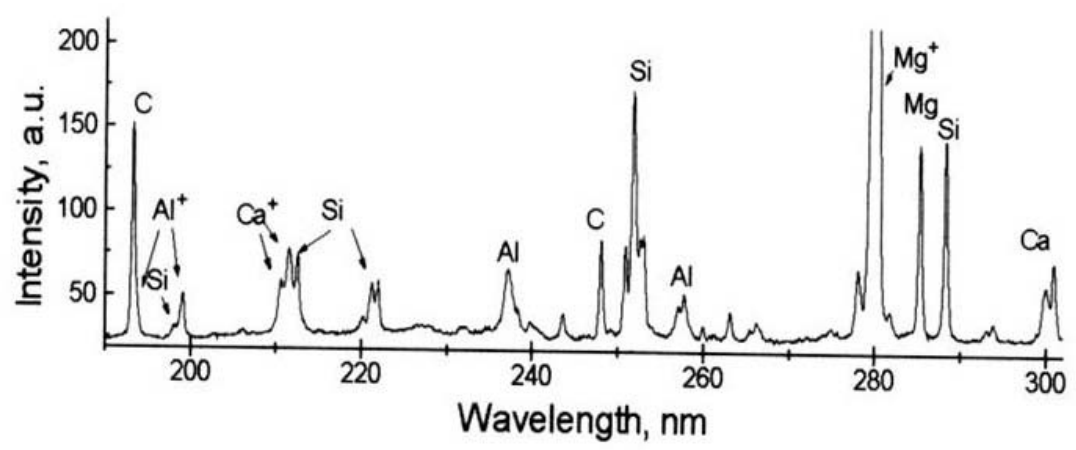

Fig. 4. LIPS spectra of coating with mixed calcium carbonate and kaolin pigment. 


\section{EXPERIMENTAL}

Base paper samples used in this study were produced on commercial paper machines. They were then pilot-coated using both pilot blade and film coaters. Base and LWC data are tabulated in Table 1.

Table 1. Pertinent Data for the LWC Paper Used in this Study

\begin{tabular}{lllll}
\hline Base paper & $\begin{array}{l}\text { Original basis } \\
\text { weight } \\
\left(\mathrm{g} / \mathrm{m}^{2}\right)\end{array}$ & LWC paper & Forming method & $\begin{array}{l}\text { Coat weight } \\
\left(\mathrm{g} / \mathrm{m}^{2}\right)\end{array}$ \\
\hline P2 & 37 & Kp 404 & film & 9 \\
P14 & 37 & Kp 436 & blade & 9 \\
P5 & 36 & Kp 419 & film & 5 \\
P17 & 36 & Kp 445 & blade & 5 \\
P3 & 40 & Kp 410 & film & 9 \\
P15 & 40 & Kp439 & blade & 9 \\
Former A & NA & Kp 404A & film & NA \\
Former B & NA & Kp 421 & film & NA \\
\hline
\end{tabular}

Variables that were investigated in this work include coat weight, coating methodology, and impact of the former used in base paper production on coating characteristics. The LIPS method was used as the principle method of compositional analysis.

\section{Generation of LIPS Spectra}

For each coated sample, 3-dimensional spatial maps of coating distributions were produced using the previously described home-built laboratory-grade LIPS system at the Department of Chemistry, University of Jyväskylä in Finland. This was accomplished by analyzing a $4 \mathrm{~cm}^{2}$ area of each sample. Coating layers were completely removed by 20 laser pulses in each xy-position. In each experiment, sample-to-sample collection from center was $500 \mu \mathrm{m}$ for a total of 1600 points for each $4 \mathrm{~cm}^{2}$ area. The top and bottom side of each sample was analyzed. Additionally, each coated sample was analyzed along a line [either MD or CD] at $100 \mu \mathrm{m}$ centers, both top and bottom side, to provide a $10 \mathrm{~cm}$ coating distribution profile. Again, coatings were completely removed by directing 20 pulses at each xy-position. Similarly, base papers were analyzed to provide $10 \mathrm{~cm}$ filler profile distributions. The base papers were measured at $200 \mu \mathrm{m}$ centers and 5 pulses were directed at each xy-position. Top and bottom sides of each base paper were measured. The spectral emission data was saved in a matrix format and the data were then manipulated using MATLAB graphics software to produce graphic images shown in this manuscript. 


\section{SEM Analyses}

Before the actual spectroscopy was carried out, it was decided to characterize the LWC paper using scanning electron microscopy (SEM). Following the spectroscopic analysis, further characterization of both the base papers and their coated equivalents was also conducted in order to compare the LIPS results with SEM. The samples were embedded in spur resin, polished and etched. A plasma coating of $\mathrm{Au} / \mathrm{Pd}$ was applied to provide electrical conductivity. The instrument used was a JEOL JSM-6400 SEM with LaB6, operated at $10 \mathrm{kV}$ accelerating potential.

\section{Paper Testing}

Both LWC and base paper were characterized by physical tests. There were several reasons for doing this. Foremost was the fact that two different formers were used to make base paper that was later film-coated. Therefore a comparison of these base papers, and by inference, the actual formers, required characterization of the samples. Secondly, it should be noted here that this study was part of a larger study on light-weight coatings carried out by a company. Apart from the proprietary nature of a number of the results, certain data were not available to the author. For both formers, neither the basis weights nor coat weights for the base papers and the LWC papers, respectively, were known. Finally, by conducting surface smoothness tests on both base papers and LWC papers, a comparison with LIPS results could be made. Base paper properties and characteristics determined included average basis weight, Sheffield smoothness of both top and bottom sides, Gurley porosity, hard and soft platen caliper, and hard and soft density. For the coated papers, an average coat weight and surface smoothness were determined. Paper testing was done in accordance with TAPPI Standard Methods.

\section{Burnout Testing}

The burnout test, also known as binder burnout, is a traditional test used by papermakers to characterize the coating coverage of a coated sheet of paper by using image analysis to scan the sheet (O'Neill and Jordan 2000). The burnout test was used to characterize both coated and uncoated sheets. Image analysis was then used to make both quantitative and qualitative assessments of coating characteristics of the samples. The results obtained were useful in assessing the validity of the LIPS application to coated paper.

The procedure for the test, as used in this work, is as follows. A salt solution is prepared consisting of $25 \mathrm{~g}$ of ammonium chloride dissolved in $1 \mathrm{~L}$ of 50/50 deionized water/methanol. The paper sample is completely immersed for several minutes in the solution and removed and allowed to fully dry in air. The sample is then charred in a muffle oven for 6 min. at $225^{\circ} \mathrm{C}$. Chemical pulp fibers turn black, while mechanical pulp fibers turn brown; the inorganic pigment remains largely unaffected.

For the image analysis, a $2.5 \times 2.5 \mathrm{~cm}$ square of paper was scanned using a 1200 dpi UMAX PowerLook Scanner. A scanning program, Scion Image-Beta 4.02, was then used to measure the area of dark (fibers) against a white (pigment) background. The Scion Image program has 256 gray levels, and assigns 0 to white and 255 to black. 


\section{RESULTS AND DISCUSSION}

\section{Paper Testing Results}

The results of physical tests conducted on both base papers and their coated equivalents provided a context in which to compare these results with analyses obtained from LIPS. Paper testing data are reported in Table 2.

Table 2. Base Paper Data

\begin{tabular}{|l|l|l|l|l|l|l|l|l|}
\hline Sample \# & $\begin{array}{l}\text { Average } \\
\text { basis } \\
\text { weight } \\
\left(\mathrm{gm} / \mathrm{m}^{2}\right)\end{array}$ & $\begin{array}{l}\text { Smoothness } \\
\text { (Sheffield units) }\end{array}$ & $\begin{array}{l}\text { Porosit } \\
\text { top }\end{array}$ & $\begin{array}{l}\text { bottom } \\
(\text { Gurley } \\
\mathrm{sec})\end{array}$ & $\begin{array}{l}\text { Hard } \\
\text { platen } \\
\text { caliper } \\
(\mathrm{mm})\end{array}$ & $\begin{array}{l}\text { Soft } \\
\text { platen } \\
\text { caliper } \\
(\mathrm{mm})\end{array}$ & $\begin{array}{l}\text { Hard } \\
\text { density } \\
\left(\mathrm{kg} / \mathrm{m}^{3}\right)\end{array}$ & $\begin{array}{l}\text { Soft } \\
\text { density } \\
\left(\mathrm{kg} / \mathrm{m}^{3}\right)\end{array}$ \\
\hline P5/P17 & 36.66 & 214 & 168 & 31.94 & .0627 & .0497 & 584.7 & 737.6 \\
\hline P2/P14 & 38.00 & 183 & 180 & 50.00 & .0630 & .0494 & 603.2 & 769.2 \\
\hline P3/15 & 41.39 & 208 & 177 & 86.34 & .0716 & .0569 & 578.1 & 727.4 \\
\hline Former A & 41.51 & 161 & 200 & 59.02 & .0673 & .0549 & 616.8 & 756.1 \\
\hline Former B & 43.92 & 173 & 200 & 49.5 & .0741 & .0600 & 592.7 & 732.0 \\
\hline
\end{tabular}

The labels used for sample identification for both coated and uncoated papers were based solely on locations within the reel of paper.

Because coat weights were not provided for the LWC papers using Former A and Former B base papers, they were calculated from measurements obtained from the samples. The mean measured basis weight of the base paper was subtracted from the mean measured basis weight for their coated equivalents. Basis weight data was available for base papers P5/P17, P2/P14 and P3/15. Coat weight data was also available for their coated equivalents. Mean measured coat weights were also determined for these papers by the same method to check the validity of the measurements. Coat weight data measurements are tabulated in Tables 3 and 4.

Table 3. Coated Paper Data

\begin{tabular}{|l|l|l|l|l|l|l|}
\hline LWC \# & $\begin{array}{l}\text { Base } \\
\text { paper } \\
\text { equivalen } \\
\mathrm{t}\end{array}$ & $\begin{array}{l}\text { Mean LWC } \\
\text { basis } \\
\text { weight } \\
\left(\mathrm{g} / \mathrm{m}^{2}\right)\end{array}$ & $\begin{array}{l}\text { Mean } \\
\text { base } \\
\text { paper } \\
\text { weight } \\
\left(\mathrm{g} / \mathrm{m}^{2}\right)\end{array}$ & $\begin{array}{l}\text { Mean coat } \\
\text { weight per } \\
\text { side }\left(\mathrm{g} / \mathrm{m}^{2}\right)\end{array}$ & $\begin{array}{l}\text { Reported } \\
\text { coat weight } \\
\left(\mathrm{g} / \mathrm{m}^{2}\right)\end{array}$ & $\begin{array}{l}\text { Coat } \\
\text { weight } \\
\text { used } \\
\left(\mathrm{g} / \mathrm{m}^{2}\right)\end{array}$ \\
\hline $\begin{array}{l}\text { Kp404/43 } \\
6\end{array}$ & P2/P14 & 56.66 & 38.00 & 9.328 & 9 & 9 \\
\hline $\begin{array}{l}\text { Kp419/44 } \\
5\end{array}$ & P5/P17 & 46.39 & 36.66 & 4.87 & 5 & 5 \\
\hline $\begin{array}{l}\text { Kp410/43 } \\
9\end{array}$ & P3/P15 & 58.43 & 41.39 & 8.52 & 9 & 9 \\
\hline Kp404A & Former A & 52.40 & 41.51 & 5.45 & NA & 5 \\
\hline Kp421 & Former B & 61.33 & 43.92 & 8.705 & NA & 9 \\
\hline
\end{tabular}


Table 4. Smoothness Data of Coated Papers

\begin{tabular}{|l|l|l|}
\hline \multirow{2}{*}{ Coated Sample } & \multicolumn{2}{|l|}{ Sheffield smoothness (S.U.) } \\
\cline { 2 - 3 } & Side 1 & Side2 \\
\hline Kp 404 & 38 & 34 \\
\hline Kp 436 & 20 & 21 \\
\hline Kp 419 & 48 & 54 \\
\hline Kp 445 & 43 & 39 \\
\hline Kp 410 & 35 & 34 \\
\hline Kp 439 & 18 & 14 \\
\hline Former A & 43 & 33 \\
\hline Former B & 35 & 34 \\
\hline
\end{tabular}

\section{Coating Pigment Analysis}

The results from the analyses indicated that the coating pigment and filler used in all samples was kaolin. Since no differences were noted in plasma emission spectra from layer to layer, it was concluded that a single coating was applied to each of the base papers. Analyses were conducted for $\mathrm{Si}$ and $\mathrm{Mg}$ once the filler and coating pigment was determined to be kaolin. Specifically, the Si line of wavelength $288 \mathrm{~nm}$ was used to detect the presence of the coating. Since the coating contains a high proportion of kaolin, the composition of which is directly proportional to $\mathrm{Si}$, the $\mathrm{Si}$ emission intensity must therefore be a semi-quantitative analysis of pigment distributions (since Si impurities can affect the signal correlation).

\section{Coat Weight Distributions}

By producing 3-dimensional spatial distribution maps of coating coverage, a visual analysis of coat weight distributions was possible. Histogram plots showing frequency distributions of spectral line intensities provide a semi-quantitative treatment of the same data.

Fig. 5 illustrates the difference between film-coated paper with a coat weight of 9 $\mathrm{gm} / \mathrm{m}^{2}$ and one with a coat weight of $5 \mathrm{gm} / \mathrm{m}^{2}$. The spatial distribution maps illustrate variations in coat weight across the sample area. Fig. 6 is a coating distribution profile for the same papers. The Si line intensities are color scaled in accordance with the visible light spectrum. For all results discussed herein pertaining to both spatial distribution maps and coating profile maps, the most intense oranges reflect the highest spectral line intensities. Conversely, the most intense blues reflect the lowest spectral line intensities.

In the paper with the $9 \mathrm{gm} / \mathrm{m}^{2}$ coat weight, approximately 10 pulses were required to completely remove the coating. In the paper with the $5 \mathrm{gm} / \mathrm{m}^{2}$ coat weight, 6 to 7 pulses were needed. Visual inspection of the maps indicate that base paper is exposed through the lower coat weight after the first laser shot, and it is very likely that base paper is exposed through the unablated surface. 

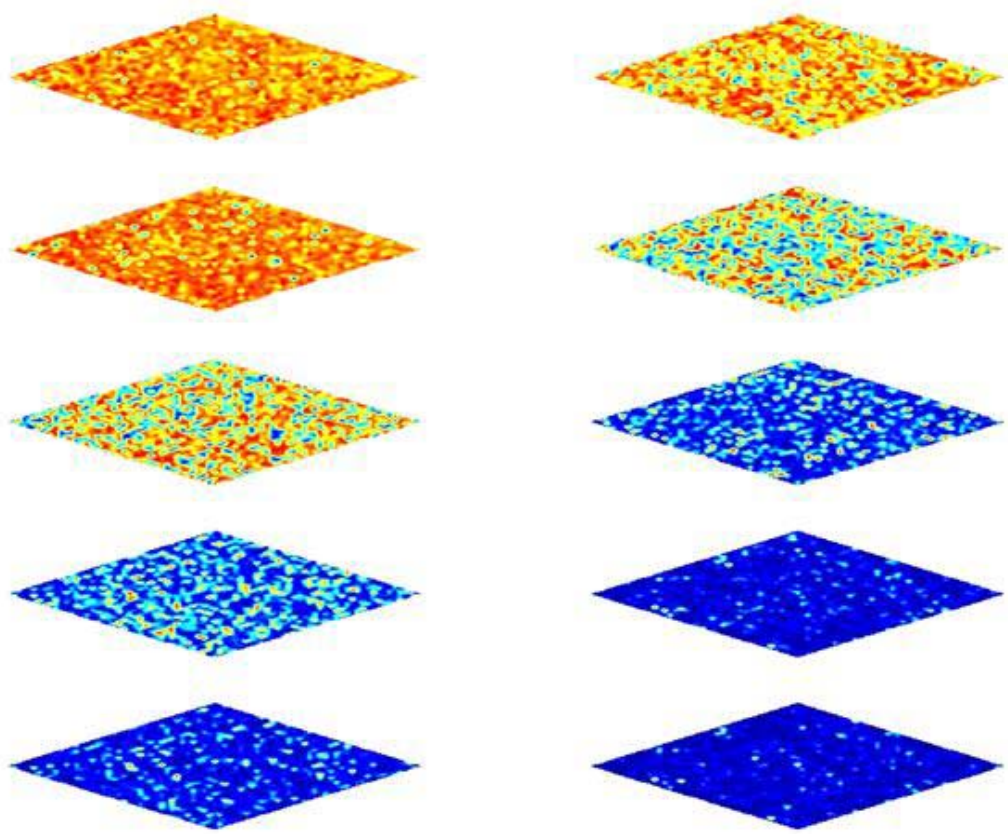

Fig. 5. Coating distribution in film-coated paper. Left image: coat weight $9 \mathrm{gm} / \mathrm{m}^{2}$; Right image: coat weight $5 \mathrm{~m} / \mathrm{m}^{2}: 1,2,5,10$, and 15 pulses.
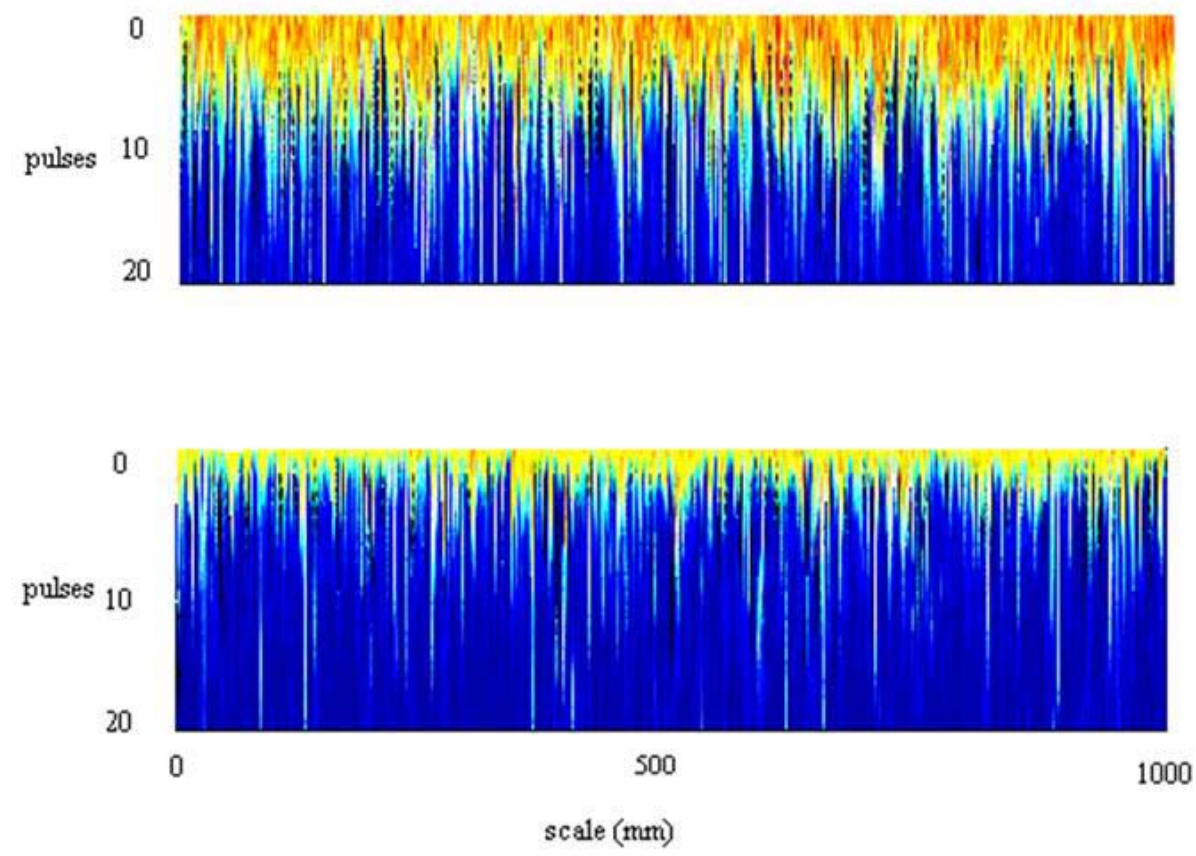

Fig. 6. Coating distribution profile of $9 \mathrm{~g} / \mathrm{m}^{2}$ (top) and $5 \mathrm{~g} / \mathrm{m}^{2}$ (bottom) film-coated paper. 
Burnout images of the coated papers support the idea that the base stock is at least partly exposed through the unablated surfaces of coated samples. Fig. 7 contains burnout images of $9 \mathrm{gm}$ and $5 \mathrm{gm}$ coat weight papers, respectively. By thresholding the images, surface coating coverage can be estimated. Coating coverage for the $9 \mathrm{~g} / \mathrm{m}^{2}$ paper was $93 \%$, while coating coverage for the $5 \mathrm{~g} / \mathrm{m}^{2}$ paper was $84 \%$. Visual inspection of both burnout images shows clearly that there are more fibers exposed at the surface of the 5 gm coat weight paper.

Studying histograms that show frequency distributions of Si line intensities can also aid in assessing coating coverage. Fig. 8 shows three-dimensional spatial distributions of the same two film-coated papers. The coating distribution maps reflect the removal of the second coating layer in each case. Their associated frequency distribution plots of $\mathrm{Si}$ emission intensities are indicative of the coating coverage and coat weight distribution.

It is evident that the coating coverage and coat weight distribution is less uniform for the lighter coat weight, with a skew of distributions towards the lower Si emission intensities. Film coating is essentially contour coating, in that the application follows the naturally undulating surface of the base sheet. It is therefore reasonable to assume that the coating thickness should be fairly uniform and, by inference, that the Si line intensities should have a tight distribution. This is clearly evident in the higher coat weight. At coat weights as low as $5 \mathrm{~g} / \mathrm{m}^{2}$, it is not unreasonable to see a broader distribution.

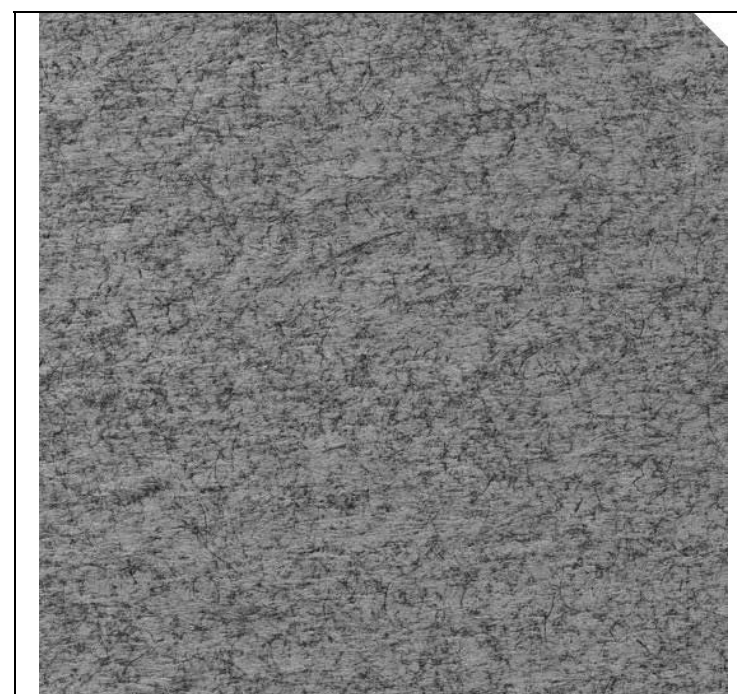

A

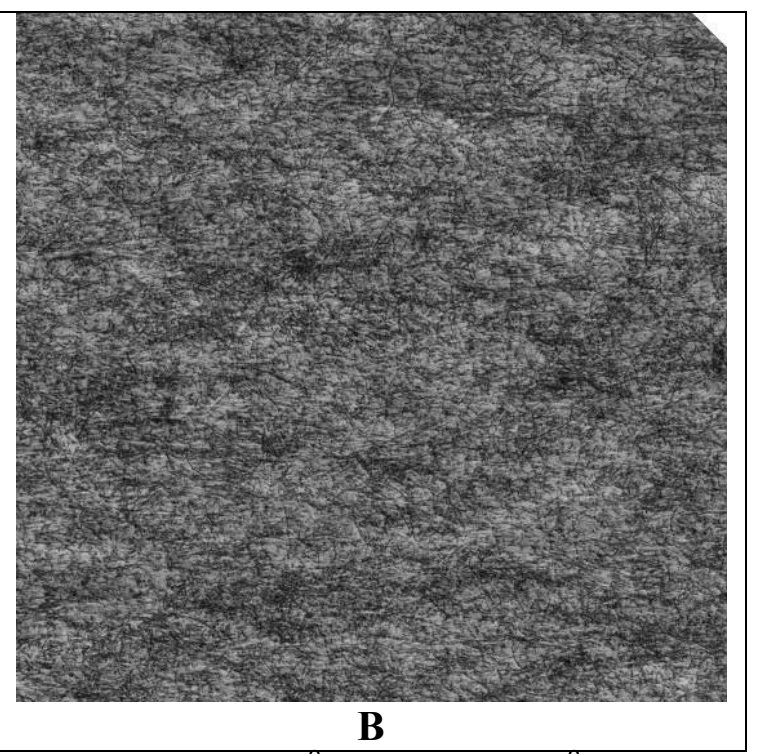

B

Fig. 7. Burnout images of coated paper in which coat weight is $9 \mathrm{~g} / \mathrm{m}^{2}$ for $A$ and $5 \mathrm{~g} / \mathrm{m}^{2}$ for $B$. 

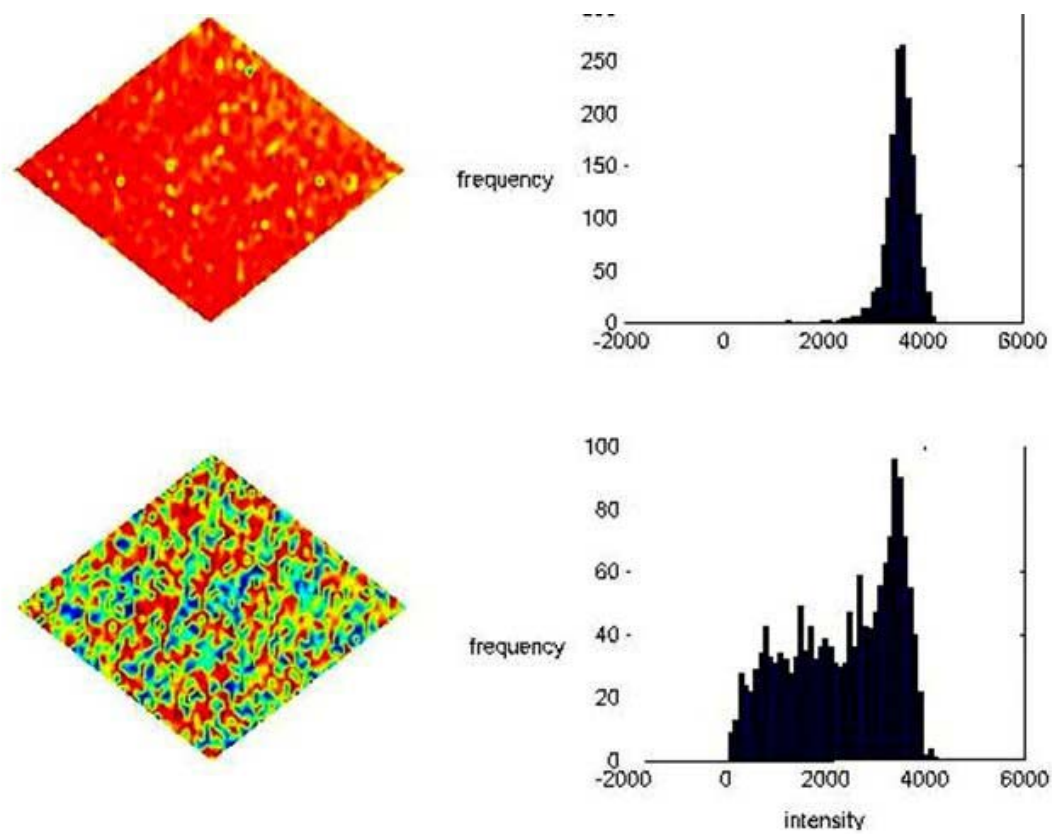

Fig. 8. Frequency distribution plots of Si line intensity for $9 \mathrm{gm}$ and $5 \mathrm{gm}$ coat weights, film-coated paper; second ablated layer.

\section{Film Versus Blade Coating}

Two traditional methods used to coat papers are the film coating and blade coating methods. With film coating, coating color is metered onto the coating roll and transferred onto the paper in a roll nip. With blade coating, an excess of coating color is first applied to the paper and then scraped off with a blade. Both coating methods result in different surface properties or characteristics of the coated paper. Fig. 9 illustrates this difference.
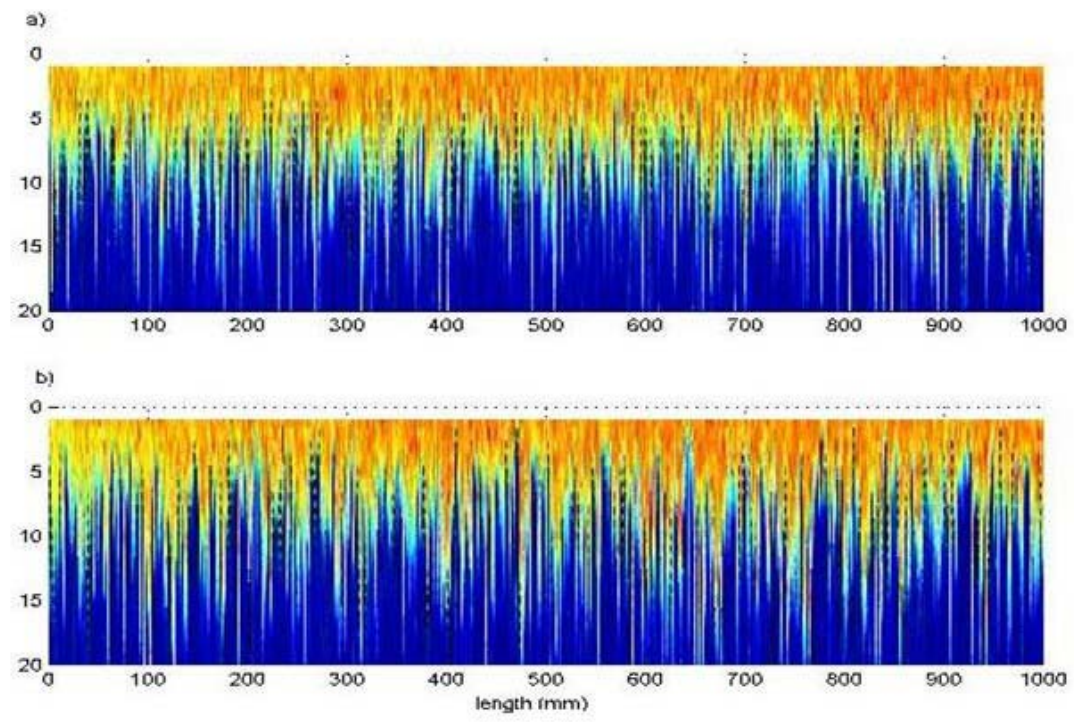

Fig. 9. Coating distribution profile in (top-a) film-coated paper and (bottom-b) blade-coated paper. Coat weights are $9 \mathrm{~g} / \mathrm{m}^{2}$. 
Blade coaters trade greater surface smoothness of the coated paper in exchange for a less even coat weight distribution. Low relief areas in the naturally undulating base paper surface receive a thicker coating than high relief areas. This is evident in the coating distribution profile, where area and points of low Si emission intensity represent those high relief areas and thus a very thin coating layer. The film-coated papers, according to their coating distribution profile, display a more even coat weight distribution, which in turn is a trade-off for the smoother sheet surface provided by the blade coater. Smoothness data for the coated papers support this interpretation of LIPS. In each case, the blade-coated versions of the base papers yield lower Sheffield unit values.

Histogram plots for the same film and blade coated papers are illustrated in Fig. 10. Three-dimensional spatial distribution maps of the same coated papers are shown in Fig. 9. The distribution for the blade-coated paper shows a tailing of low line intensities that do not appear in the film-coated paper.

a)
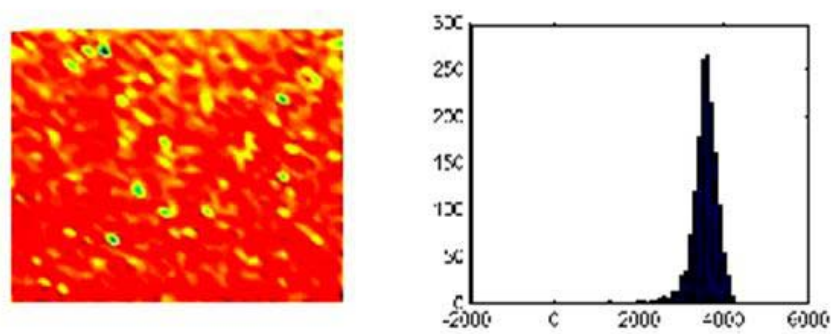

b)

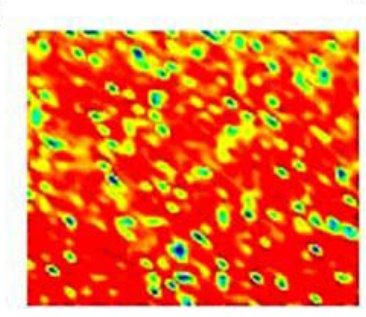

frequency

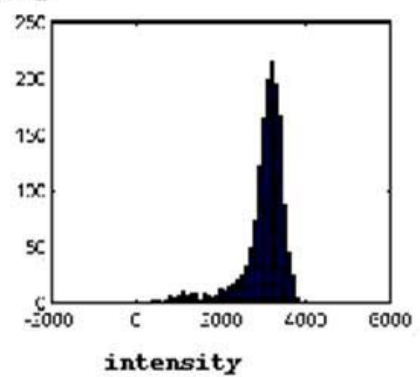

Fig. 10. Frequency distribution plots of Si line intensity in a) film-coated paper and b) blade- coated paper. Coat weight $9 \mathrm{gm} / \mathrm{m}^{2}$.

A high frequency of strong Si signals was noted in the case of blade-coated paper. The higher frequency of lower coat weights for the blade coated papers are indicative of small or shallow voids in the paper surface that are leveled in the blade coating process. This is consistent with what LIPS is indicating: blade coating provides a smoother sheet. By contrast, the film-coated paper shows a normal distribution in a tight range of signal intensities, consistent with a more even coat weight.

\section{Binder Migration}

Binder migration is the adventitious movement of binder after application of the coating color to the base paper. It may be caused by surface tension force pulling liquid 
(mainly water) into pores, carrying some binder with it or by evaporative drying in the dryer section (Casey 1985).

Binder migration is evident, however, when looking at Si emission signals from the first laser pulse to the second laser pulse of ablated coating layers. Si emission intensity is larger for the second pulse because binder migration to the surface of the coating effectively reduces the amount of coating pigment in the volume of ablated material. This results in lower Si emission intensities in the first ablated layer relative to the second one. This effect is illustrated in Fig. 11.
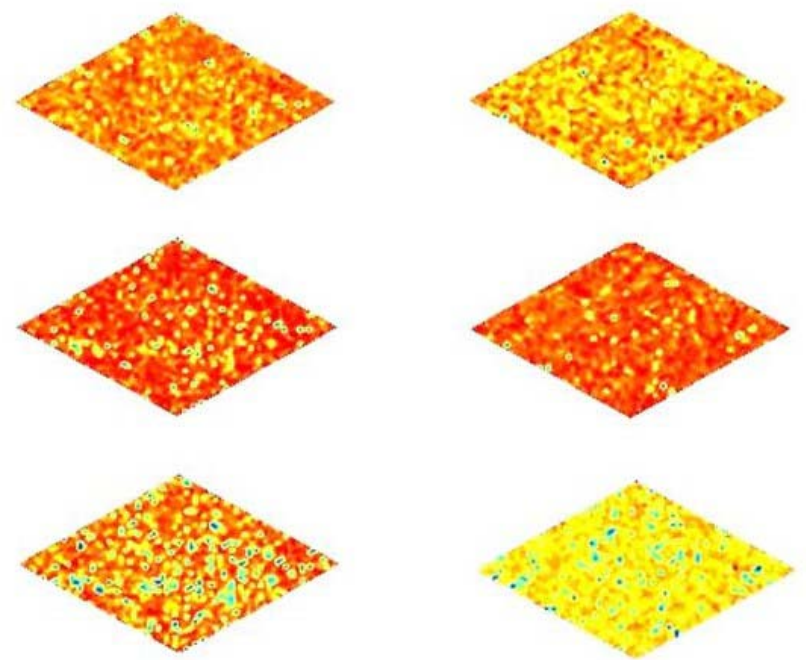

Fig. 11. Binder migration effect illustrated in coating distribution maps of film-coated (left) and blade-coated (right) paper. First (top), second (middle) and third (bottom) pulses. Note the difference between second and third pulse.

\section{Basis Weight Effects}

Figure 12 shows coat weight distributions for two film-coated papers with equal coat weights of $9 \mathrm{~g} / \mathrm{m}^{2}$.

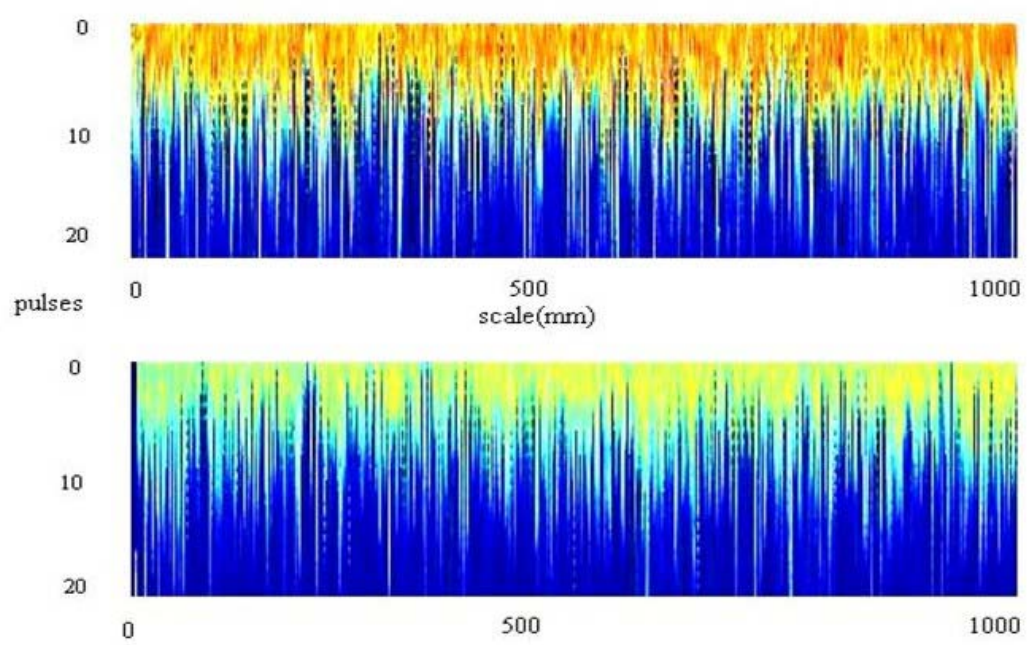

Fig. 12. Coating weight distribution profiles of film-coated paper. Base paper basis weights are 37 $\mathrm{g} / \mathrm{m}^{2}$ (top) and $40 \mathrm{~g} / \mathrm{m}^{2}$ (bottom). Coat weight $9 \mathrm{~g} / \mathrm{m}^{2}$. 
The base paper basis weights for the top and bottom profiles are $37 \mathrm{~g} / \mathrm{m}^{2}$ and 40 $\mathrm{g} / \mathrm{m}^{2}$, respectively. From the coating distribution profiles, it is evident from the LIPS signal that there is a higher coat weight distribution at the surface of the lower grammage paper. From paper testing results, the heavier paper appears less porous than the lighter one (porosity of 86.34 Gurley sec compared to 31.94 Gurley sec). Since the coat weights are the same $\left(9 \mathrm{~g} / \mathrm{m}^{2}\right)$, the LIPS signal should be slightly higher, if anything, for the less porous sheet since coating color is less likely to penetrate as deeply when applied. Frequency distribution plots for both papers (Fig. 13) show that there is a greater frequency of higher emission line intensities for the lower basis weight paper, again consistent with a higher surface coat weight compared to the heavier paper.

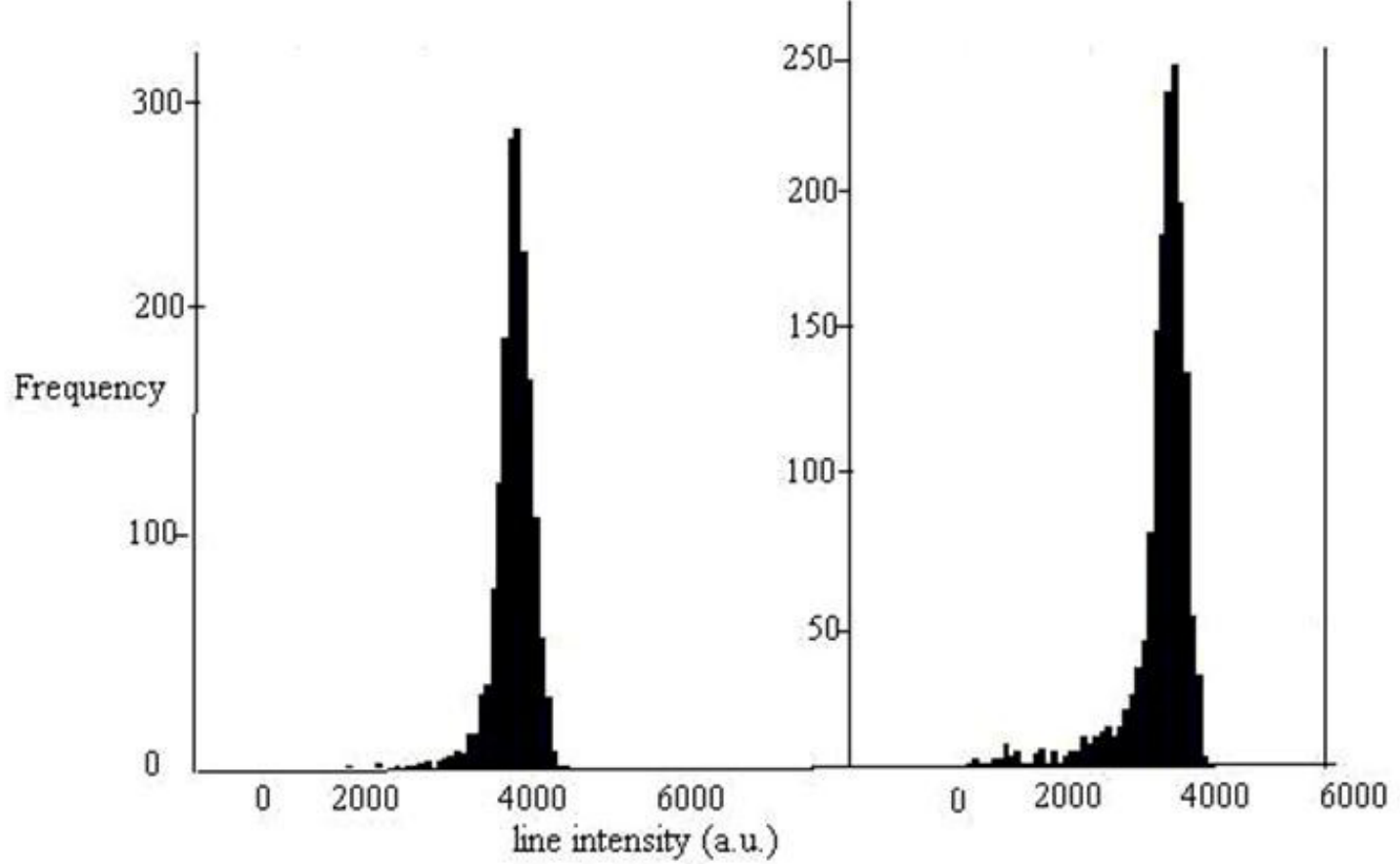

Fig. 13. Frequency distribution of $\mathrm{Si}$ line intensity for different basis weight papers (left plot is 37 $\mathrm{g} / \mathrm{m}^{2}$ while the right is $\left.40 \mathrm{~g} / \mathrm{m}^{2}\right)$ with the same coat weight $\left(9 \mathrm{~g} / \mathrm{m}^{2}\right)$.

The same results were obtained with blade-coated papers using the same base papers and coat weights. It was thought that binder migration in the heavier sheet might be responsible for the lower signals, since, if the pigment could not penetrate the base paper, it was possible that the binder may have concentrated at the surface as well. Fig. 14 shows spatial distribution maps for both papers. The maps indicate that there does not seem to be any effect in signal intensity due to binder migration. 


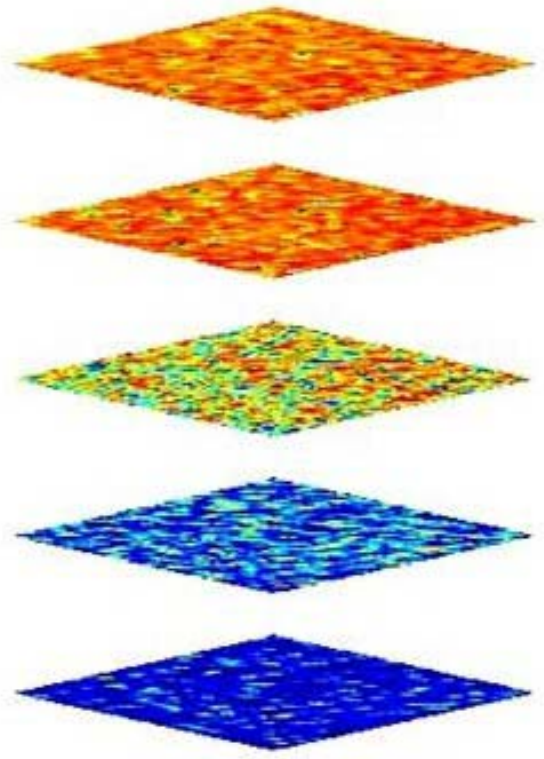

$37 \mathrm{gm}$ basis weight
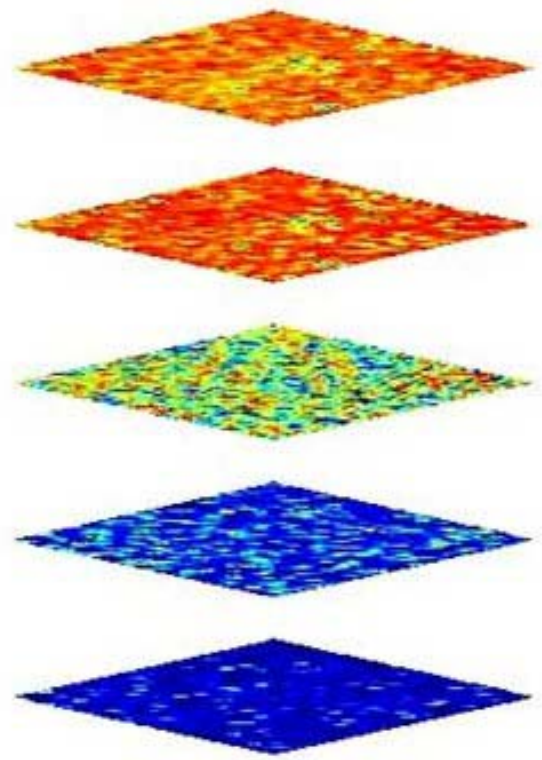

$40 \mathrm{gm}$ basis weight

Fig. 14. Spatial coating distribution maps for high and low basis weight papers.

\section{CONCLUSIONS}

1. Pigment identification within light-weight paper coatings is possible by identifying the elemental composition of the pigment. Since each element emits spectra at its characteristic wavelengths, the elemental composition of the pigment can quickly be determined. Coat weight distribution maps and profiles can be created based on spectral emission intensities of the signature elements. This is made possible by coupling the LIPS data with suitable software graphics.

2. Coating technologies, such as blade and film coating, generate noticeably different coating distribution profiles that can be detected by LIPS. Interpretation of coating distribution maps and profiles, coupled with smoothness data of the coated sheet allowed a qualitative assessment of the coating technologies, to the point of determining differences in distribution of coating in the substrates.

3. Coat weight variations are characterized by the relative intensities of spectral emission lines of its elements. Coat weight distribution maps and profiles were used to identify areas of poor coating coverage in very light coatings. Histogram plots of $\mathrm{Si}$ line intensities proved useful in interpreting variations in coating coverage for different coat weights. Burnout images were useful in confirming the results. 


\section{ACKNOWLEDGMENTS}

The authors are grateful to the Institute of Paper Science and Technology Center at the Georgia Institute of Technology whose research funding made this work possible. This research allowed BW to partially fulfill his requirements for the M.Sc. degree.

\section{REFERENCES}

Anglos, D., Couris, S., and Fotakis, C. (1997). "Laser diagnostics of painted artworks: Laser induced breakdown spectroscopy in pigment identification," Appl. Spec. 51(7), 1025-1030.

Autin, M., Briand, A., Mauchien, P., and Mermet, J. M. (1993). "Characterization by emission spectroscopy of a laser-produced plasma from a copper target in air atmospheric pressure," Spectrochem. Acta 48(6/7), 851-862.

Baudelet, M., Guyon, L., Yu, J., Wolf, J.-P., Amodeo, T., Frejafon, E., and Laloi, P. (2006). "Femtosecond time-resolved laser - induced breakdown spectroscopy for detection and identification of bacteria: A comparison to the nanosecond regime." $J$. Appl. Phys. 99(8), 084701/1-084701/9.

Casey, J. P. (1985). Pigment Coated Papers - A Critical Assessment of the Processes, Technical Developments, and Economics. Marcel Dekker, Inc., New York.

Chen, Y., Bulatov, V., Singer, L., Stricker, J., and Schechter, I. (2005). "Mapping and elemental fractionation of aerosols generated by laser - induced breakdown ablation." Anal. Bioanal. Chem. 383(7-8), 1090-1097.

Grant, K., Paul, G., and O’Neill, J. (1991). "Quantitative elemental analysis of iron ore by laser induced breakdown spectroscopy," Applied Spec. 45(4), 701-705.

Hakkanen, H. (1998). "Development of a method based on laser induced plasma emission spectrometry for rapid spatial analysis of material distributions in paper coatings," Ph.D. dissertation, University of Jyväskylä, Jyväskylä, Finland.

Hakkanen, H. J., and Korppi-Tommola, E. I. (1998). "Laser-induced plasma emission spectrometric study of pigments and binders in paper coatings: matrix effects," Anal. Chem. 70(22), 4724-4729.

Hakkanen, H. J. and Korppi-Tommola, E. I. (1995). "UV-plasma study of elemental distributions of paper coatings," Appl. Spec. 49(12), 1721-1728.

Hakkanen, H. J., and Korppi-Tommola, J. E. I. (1993). "Laser-induced fluorescence imaging of paper surfaces," Appl. Spec. 47(12), 2122-2125.

Heitz, J., Pedarnig, J. D., Baurle, D., and Petzow, G. (1997). "Excimer-laser ablation and micro-patterning of ceramic $\mathrm{Si}_{3} \mathrm{~N}_{4}$," Appl. Phys. A65, 295-261.

Kartovaara, I. (1989). "Coatweight distribution and coating coverage in blade coating," Paperi ja Puи 9, 134-140.

Lee, Y., Song, K., and Sneddon, J. (1996). Lasers in Analytical Atomic Spectroscopy. Chapter 5. John Wiley \& Sons, New York.

Maiman, T. H. (1960). "Optical maser action in ruby," Brit. Commun. \& Electron. 7, 4674-675. 
O’Neill, M., and Jordan, B. (2000). “The burnout test revisited,” J. Pulp Pap. Sci. 26(4), 131-134.

Peterson, R. A., and Williams, C. L. (1992). "Determining paper-coating thickness with electron microscopy and image analysis," Tappi J. 75(10), 122-126.

Radziemski, L., Loree, T., Cremers, D. and Hohhmann, D. (1983). "Time-resolved laserinduced breakdown spectroscopy of aerosols," Anal. Chem. 55, 1246-1252.

Eppler, A. S., Cremers, D. A., Hickmott, D. D., Ferris, M. J., and Koskelo, A. C. (1996). "Matrix effects in the detection of $\mathrm{Pb}$ and $\mathrm{Ba}$ in soils using laser-induced breakdown spectroscopy," Appl. Spec. 50(9), 1175-1181.

Samek, O., Beddows, D. C. S., Telle, H. H., Kaiser, J., Liska, M., Caceres, J. O., and Gonzales Urena, A. (2001). "Quantitative laser - induced breakdown spectroscopy analysis of calcified tissue samples." Spectrochim. Acta, Part B: Atom. Spectrosc. 56B(6), 865-875.

Sheppard, J. C., and Grant, G. (1974). "Use of positive ion backscattering in the analysis of paper coatings and filler," Tappi J. 57(3) 151-154.

Sinclair, A. R. (1975). Synthetic Binders in Paper Coatings, TAPPI Monograph Series, No. 36, TAPPI Press, Atlanta.

Smook, G. A. (1992). Handbook for Pulp and Paper Technologists (2 ${ }^{\text {nd }}$ Ed.) Angus Wilde Publications, Vancouver, BC, Canada.

Wang, S., Brown, R., and Grey, J. D. (1994). "Application of laser ablation-ICPMS to the spatially resolved micro-analysis of biological tissue," Appl. Spec. 48(11), 1321-1325.

Whitehouse, A. I. (2006). "Laser - induced breakdown spectroscopy and its application to the remote characterisation of hazardous materials." Spectrosc. Europe 18(2), 14, $16-21$.

Article submitted: April 17, 2006; Revision accepted: June 29, 2006; Published July 15, 2006 